\title{
The relationship between critical pressure and width of gas vesicles in isolates of Planktothrix rubescens from Lake Zürich
}

\author{
D. I. Bright and A. E. Walsby
}

Author for correspondence: A. E. Walsby. e-mail: A.E.Walsby@bristol.ac.uk

School of Biological Sciences, University of Bristol, Woodland Road, Bristol BS8 1UG, UK

\begin{abstract}
The mean critical collapse pressure $\left(p_{c}\right)$ of gas vesicles in 81 strains of the cyanobacterium Planktothrix rubescens from Lake Zürich, Switzerland, was bimodally distributed between a minimum of $0.86 \mathrm{MPa}$ and a maximum of 1.17 MPa. Measurements were made of the cylinder diameter (d) of gas vesicles isolated from seven of the strains. The mean diameter, which varied from 48 to $61 \mathrm{~nm}$, was inversely related to $p_{c^{\prime}}$ in keeping with the theory of strength of thin-walled rigid cylinders. These measurements extended the range of $p_{c}$-width relationship of gas vesicles, which can be described by the expression $p_{c}=461(d / n m)^{-1.53} \mathrm{MPa} . p_{c}$ was correlated with gas vesicle genotype (see the accompanying paper by S. J. Beard, B. A. Handley, P. K. Hayes \& A. E. Walsby, Microbiology 145, 2757-2768): of the 81 strains investigated, all those with the gas vesicle genotype GV2 produced gas vesicles with a mean $p_{c}$ of less than 1.0 MPa, whereas those of GV3 had a mean $p_{c}$ of greater than 1.0 MPa. It is suggested that gas vesicles of the GV3 strains, which are narrower and stronger than any previously recorded in freshwater cyanobacteria, have evolved to withstand the high hydrostatic pressures during deep winter mixing in Lake Zürich.
\end{abstract}

Keywords: cyanobacterial diversity, gas vesicles, Planktothrix rubescens

\section{INTRODUCTION}

Gas vesicles, which provide buoyancy in planktonic cyanobacteria, are hollow cylindrical structures (Oliver, 1994; Walsby, 1994). They are rigid but collapse at a certain threshold pressure, referred to as the critical pressure, $p_{c}$. Gas vesicles in different genera of cyanobacteria vary in width and it has been demonstrated that their mean $p_{\mathrm{c}}$ values vary inversely with width (Hayes \& Walsby, 1986; Walsby \& Bleything, 1988). This inverse relationship is understood in terms of the mechanics of a thin-walled rigid cylinder (Walsby, 1991), which buckles and collapses through instability (Allen \& Bulson, 1980).

Differences in the mean $p_{c}$ of gas vesicles occur not only between different genera but also between different species of the same genus, e.g. between different species of Anabaena, Oscillatoria and Trichodesmium; it has

Abbreviation: $p_{c^{\prime}}$ critical pressure. been suggested that these differences evolved through natural selection to withstand pressures generated by vertical mixing in natural waters (Walsby \& Bleything, 1988; Walsby, 1994). Substantial differences have been found in the mean $p_{\mathrm{c}}$ of gas vesicles in different populations of Nodularia spp. from the Baltic Sea, which may be adapted to regions of different depth (Walsby et al., 1995). It has been demonstrated that there are differences in the widths of gas vesicles in these Nodularia populations (Komárek et al., 1993; Albertano et al., 1996) but the relationship between strength and width in these populations has not been directly investigated.

Variations in gas vesicle $p_{\mathrm{c}}$ have also been demonstrated in populations of the planktonic species of Oscillatoria, which are now reclassified in the genus Planktothrix (Anagnostides \& Komárek, 1988). In a green-coloured Planktothrix (Oscillatoria) agardhii var. isothrix from Deming Lake, Minnesota, the mean $p_{\mathrm{c}}$ was $0.75 \mathrm{MPa}$ (Walsby \& Klemer, 1974) whereas in a red-coloured $P$. agardhii from Lake Gjersjøen, Norway, the mean $p_{\mathrm{c}}$ was over 0.9 MPa (Walsby et al., 1983; Walsby \& Bleything, 
1988). In P. rubescens from Lake Nantua, France, the mean $p_{c}$ may have been even higher: the apparent critical pressure $\left(p_{\mathrm{a}}\right)$ in turgid cells was $0.82 \mathrm{MPa}$ (Feuillade, 1994); allowing for turgor pressure of at least $0 \cdot 2 \mathrm{MPa}, p_{\mathrm{c}}$ would have exceeded $1 \mathrm{MPa}$. Utkilen et al. (1985) reported mean $p_{\mathrm{c}}$ values ranging from 0.60 to 1.05 $\mathrm{MPa}$ in six strains of Planktothrix isolated from Norwegian lakes but, again, there was no direct investigation of the relationship between $p_{\mathrm{c}}$ and gas vesicle width.

Walsby et al. (1998) reported on the variation of $p_{c}$ of gas vesicles in 10 of 12 clonal isolates of Planktothrix rubescens from Lake Zürich. Beard et al. (1999) demonstrated three distinct classes of gas vesicle genotype (GV1, GV2 and GV3) in these 12 isolates, which were distinguished by differences in the sequence, size, copynumber and arrangement of the $g v p C$ genes that encode the outer-surface protein (GvpC) of the gas vesicle. In another 175 clonal isolates from the lake they found the same three classes but also distinguished subclasses (GV2a and b; GV3a and b) that differed in the number of copies of $\Omega C$, a non-coding fragment of the $g \nu p C$ gene.

We report here correlations between $p_{\mathrm{c}}$ and diameter of gas vesicles in seven of these Planktothrix strains, which extend the range and refine the description of the $p_{\mathrm{c}}$-width relationship. We also report correlations between the GV genotype and $p_{\mathrm{c}}$ in 81 of these strains that suggest that variations in the $g v p C$ gene affect the size and strength of gas vesicles. The gas vesicles in many of these Lake Zürich strains are stronger than previously encountered in freshwater lakes; the occurrence of strains that produce such strong gas vesicles may be restricted to lakes that are of comparable depth.

\section{METHODS}

Cultures. Measurements were performed on 81 strains of Planktothrix rubescens cultured in $250 \mathrm{ml}$ Erlenmeyer flasks under an incident photon irradiance of $15-20 \mu \mathrm{mol} \mathrm{m}^{-2} \mathrm{~s}^{-1}$ and at a temperature of $21^{\circ} \mathrm{C}$. Detailed measurements were made on seven of the strains, Pla 9303, 9316, 9401 and 9402 isolated from Lake Zürich in 1993-4 (Walsby et al., 1998), and strains Pla 9707, 9725 and 9736 isolated in 1997 (Beard et al., 1999). Investigations of gas vesicles in these strains were made using triplicate cultures grown on a light bench illuminated with a photon irradiance of $15 \pm 2 \mu \mathrm{mol} \mathrm{m}^{-2} \mathrm{~s}^{-1}$ from below; cultures were repositioned daily in a Latin Square arrangement using randomly assigned coordinates.

Gas vesicle $\boldsymbol{p}_{\mathrm{c}}$ values. Gas vesicle $p_{\mathrm{c}}$ distributions were determined with a pressure nephelometer (Walsby, 1973). Measurements were made with $2 \mathrm{ml}$ samples of cultures mixed with $2 \mathrm{ml} \mathrm{1.0} \mathrm{M} \mathrm{sucrose} \mathrm{solution} \mathrm{to} \mathrm{remove} \mathrm{cell} \mathrm{turgor}$ pressure. The mean and standard deviation of the $p_{\mathrm{c}}$ distribution were calculated from replicate measurements by the procedure of Walsby \& Blething (1988).

Electron microscopy of gas vesicles. Pt-C replicas of flattened isolated gas vesicle were prepared for electron microscopy (Walsby \& Bleything, 1988). Measurements were made of the width $(w)$ and length $(l)$ of 158-240 flattened gas vesicles from each strain; measurements were also made of the cone side $(s)$ of 10-20 gas vesicles. The cylinder diameter was calculated as $d=2 w / \pi$. These measurements were made by converting the image of each individual gas vesicle on electron micrograph film into a digitized image in a computer bitmap using a highresolution Cohu video camera mounted on a Leica microscope in conjunction with a Synoptics Synapse Grabber. The computer image was analysed with PC_Image and Analysis software (Synoptics). At the magnifications used, one pixel in the computer image was equivalent to $0.80 \mathrm{~nm}$ on the gas vesicle, a $2 \cdot 5$-fold improvement in measurements previously made by microscope eyepiece graticule. Comparisons of electron micrographs previously measured by Walsby \& Bleything (1988) gave the same mean values but smaller standard deviations of gas vesicle widths using image analysis.

The magnification of each electron micrograph was determined by measurements of the centre line of squares in the paired image of a $463 \mathrm{~nm}$ diffraction grating. The lengths and heights of the 100 squares on each of three electron micrographs of the diffraction grating were measured for pincushion distortion: they showed that the magnification at the corner of the electron micrograph was $3.7 \%$ greater than at the centre. The mean magnification of measurements made in each of the squares, at angles from $0^{\circ}$ to $90^{\circ}$, was only $0.19 \%$ greater than the magnification determined from measurement of the centre line of squares used in the calibration.

\section{RESULTS AND DISCUSSION}

\section{The range of $p_{c}$}

$p_{\mathrm{c}}$ distributions were determined for 81 of the 185 clonal strains of Planktothrix rubescens in culture and the mean and standard deviation of $p_{\mathrm{c}}$ were calculated for each strain. The mean $p_{\mathrm{c}}$ ranged from 0.86 to $1.17 \mathrm{MPa}$ (Table 1). The overall mean $p_{\mathrm{c}}$ was $1.04 \mathrm{MPa}$ and the mean standard deviation was 0.093 MPa. The frequency distribution of $p_{c}$, in classes differing by $0.02 \mathrm{MPa}$, is shown in Fig. 1. The distribution contains two main peaks, which have modes at $0.94 \mathrm{MPa}$ and $1.14 \mathrm{MPa}$.

Seven of the strains, including examples of the three GV genotypes, were selected for more detailed study; the selection also covered the range of $p_{\mathrm{c}}$ values found in the initial survey. These strains were grown in triplicate cultures under standardized conditions for measurement of $p_{c}$ distribution (Fig. 2) and dimensions of gas vesicles (see below). Although the mean $p_{\mathrm{c}}$ values of the different strains varied by up to $0.3 \mathrm{MPa}$, the standard deviation of the $p_{\mathrm{c}}$ distributions (see Walsby \& Bleything, 1988) was similar in most cases; in Pla 9725, however, it was considerably wider (Fig. 2).

The initial selection also contained an eighth strain, Pla 9319, which was originally reported to possess strong gas vesicles (Walsby et al., 1998); this culture was evidently non-clonal because it contained two different genotypes.

\section{The range of cylinder diameter}

The mean dimensions of gas vesicles isolated from seven strains of Planktothrix rubescens are shown in Table 2. The mean cylinder diameters varied from $47.7 \mathrm{~nm}$, in strain Pla 9736, to $61.3 \mathrm{~nm}$, in strain Pla 9316. The 
Table 1. Mean $p_{c}$ values of gas vesicles in the 81 strains of Planktothrix rubescens from Lake Zürich, arranged by gas vesicle genotype

\begin{tabular}{|lcccccccc|}
\hline Genotype & $\begin{array}{r}\text { Strain } \\
(\boldsymbol{P l a})\end{array}$ & $\boldsymbol{p}_{\mathrm{c}} / \mathbf{M P a}$ & $\begin{array}{r}\text { Strain } \\
(\boldsymbol{P l a})\end{array}$ & $\boldsymbol{p}_{\mathrm{c}} / \mathbf{M P a}$ & $\begin{array}{r}\text { Strain } \\
(\boldsymbol{P l a})\end{array}$ & $\boldsymbol{p}_{\mathrm{c}} / \mathbf{M P a}$ & $\begin{array}{r}\text { Strain } \\
(\boldsymbol{P l a})\end{array}$ & $\boldsymbol{p}_{\mathrm{c}} / \mathbf{M P a}$ \\
\hline GV1 & 9303 & $0 \cdot 96$ & 9307 & $1 \cdot 00$ & 9722 & $0 \cdot 98$ & & \\
GV2a & 9304 & $0 \cdot 93$ & 9305 & $0 \cdot 86$ & 9309 & $0 \cdot 92$ & 9316 & $0 \cdot 88$ \\
& 9711 & $0 \cdot 92$ & 9713 & $0 \cdot 91$ & 9728 & $0 \cdot 87$ & 9740 & $0 \cdot 93$ \\
& 9744 & $0 \cdot 97$ & 9758 & $0 \cdot 95$ & 9760 & $0 \cdot 89$ & 9762 & $0 \cdot 97$ \\
& 9764 & $0 \cdot 89$ & 9766 & $0 \cdot 91$ & 9781 & $0 \cdot 97$ & 9783 & $0 \cdot 99$ \\
& 9790 & $0 \cdot 94$ & 9798 & $0 \cdot 94$ & 97103 & $0 \cdot 94$ & 97120 & $0 \cdot 92$ \\
& 97162 & $0 \cdot 91$ & 97127 & $0 \cdot 90$ & 97169 & $0 \cdot 93$ & 97173 & $0 \cdot 92$ \\
GV2b & 97175 & $0 \cdot 93$ & & & & & & \\
GV3a & 9731 & $0 \cdot 90$ & & & & & & \\
GV3b & 9410 & & & & & & \\
& 9401 & $1 \cdot 109$ & 9701 & $1 \cdot 14$ & 9703 & $1 \cdot 13$ & 9704 & $1 \cdot 13$ \\
& 9402 & $1 \cdot 09$ & 9706 & $1 \cdot 13$ & 9707 & $1 \cdot 14$ & 9708 & $1 \cdot 10$ \\
& 9705 & $1 \cdot 14$ & 9712 & $1 \cdot 14$ & 9714 & $1 \cdot 04$ & 9715 & $1 \cdot 09$ \\
& 9710 & $1 \cdot 13$ & 9717 & $1 \cdot 11$ & 9718 & $1 \cdot 06$ & 9719 & $1 \cdot 11$ \\
& 9716 & $1 \cdot 05$ & 9717 & $1 \cdot 09$ \\
& 9720 & $1 \cdot 15$ & 9721 & $1 \cdot 02$ & 9723 & $1 \cdot 05$ & 9725 & $1 \cdot 09$ \\
& 9726 & $1 \cdot 00$ & 9727 & $1 \cdot 16$ & 9729 & $1 \cdot 14$ & 9732 & $1 \cdot 09$ \\
& 9735 & $1 \cdot 09$ & 9736 & $1 \cdot 17$ & 9738 & $1 \cdot 11$ & 9741 & $1 \cdot 02$ \\
& 9743 & $1 \cdot 12$ & 9747 & $1 \cdot 15$ & 9751 & $1 \cdot 10$ & 9753 & $1 \cdot 13$ \\
& 9755 & $1 \cdot 09$ & 9757 & $1 \cdot 15$ & 9759 & $1 \cdot 16$ & 9761 & $1 \cdot 12$ \\
& 9763 & $1 \cdot 08$ & 9768 & $1 \cdot 11$ & 9773 & $1 \cdot 12$ & 9786 & $1 \cdot 06$ \\
& 97131 & $1 \cdot 14$ & 97150 & $1 \cdot 02$ & 97153 & $1 \cdot 09$ & 97157 & $1 \cdot 06$ \\
& 97160 & $1 \cdot 12$ & 97161 & $1 \cdot 16$ & 97164 & $1 \cdot 09$ & 97166 & $1 \cdot 01$ \\
& 97167 & $1 \cdot 14$ & 97170 & $1 \cdot 14$ & 97176 & $1 \cdot 12$ & & \\
\hline
\end{tabular}

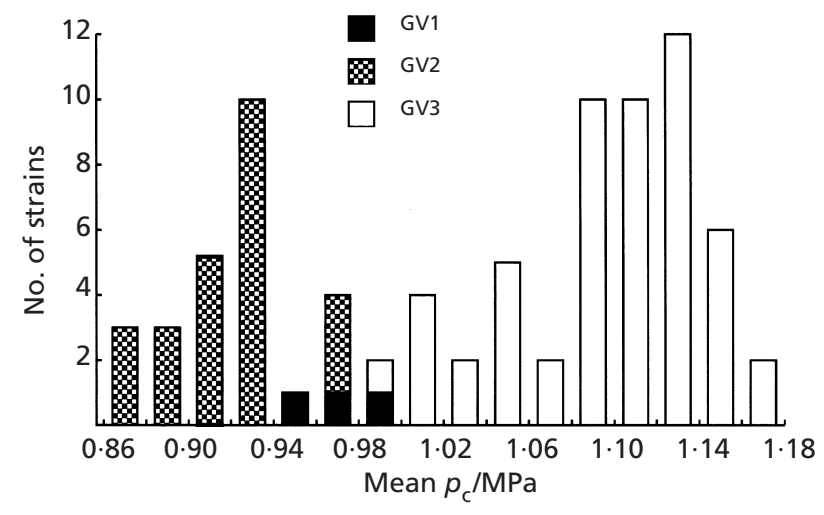

Fig. 1. Histogram of the frequency distribution of mean $p_{c}$ values of gas vesicles in 81 strains of Planktothrix rubescens.

narrowest gas vesicles previously reported in freshwater cyanobacteria were $62 \mathrm{~nm}$, in Planktothrix rubescens (Oscillatoria agardhii) strain CYA 18 (Walsby \& Bleything, 1988). The current series of measurements therefore extends the range of width previously found in freshwater cyanobacteria.

Within each strain, variation in gas vesicle width was encountered; frequency distributions of gas vesicle width are shown in Fig. 3. The distribution of gas vesicle

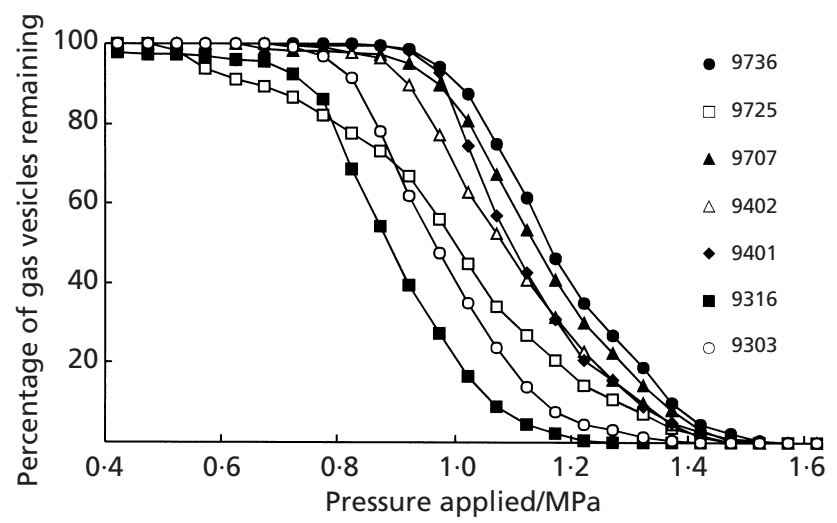

Fig. 2. $p_{c}$ distributions of gas vesicles in seven strains of Planktothrix rubescens. Symbols identify different strains listed in Table 2.

diameters was tested for normality using the Anderson-Darling test: in none of the seven strains did it depart significantly from a normal distribution.

\section{Correlation of $\boldsymbol{p}_{\mathrm{c}}$ with width of gas vesicles}

The inverse relationship between $p_{\mathrm{c}}$ and width of gas vesicles in different genera of cyanobacteria (Hayes \& 
Table 2. Dimensions and $p_{\mathrm{c}}$ values of gas vesicles isolated from seven strains of Planktothrix rubescens

The strains are bracketed into groups that show no significant difference in diameter.

\begin{tabular}{|c|c|c|c|c|c|c|c|}
\hline $\begin{array}{r}\text { Strain }(P l a) \ldots \\
\text { Gas vesicle genotype } \ldots\end{array}$ & $\begin{array}{l}{[9316]} \\
\text { GV2a }\end{array}$ & $\begin{array}{c}{[9303]} \\
\text { GV1 }\end{array}$ & $\begin{array}{l}{[9401} \\
\text { GV3a }\end{array}$ & $\begin{array}{c}9402 \\
\text { GV3b }\end{array}$ & $\begin{array}{l}9725] \\
\text { GV3b }\end{array}$ & $\begin{array}{l}{[9707} \\
\text { GV3b }\end{array}$ & $\begin{array}{l}\text { 9736] } \\
\text { GV3b }\end{array}$ \\
\hline \multicolumn{8}{|l|}{ Critical pressures } \\
\hline Mean $p_{\mathrm{c}} / \mathrm{MPa}$ & $0 \cdot 88$ & $0 \cdot 96$ & $1 \cdot 10$ & $1 \cdot 09$ & $1 \cdot 09$ & $1 \cdot 14$ & $1 \cdot 17$ \\
\hline Mean $p_{\mathrm{a}} / \mathrm{MPa}$ & $0 \cdot 61$ & $0 \cdot 72$ & $0 \cdot 81$ & $0 \cdot 88$ & $0 \cdot 80$ & $0 \cdot 82$ & $0 \cdot 79$ \\
\hline Turgor pressure/MPa & $0 \cdot 27$ & $0 \cdot 24$ & $0 \cdot 29$ & $0 \cdot 21$ & $0 \cdot 22$ & $0 \cdot 35$ & $0 \cdot 38$ \\
\hline \multicolumn{8}{|l|}{ Gas vesicle measurements } \\
\hline No. measured & 199 & 158 & 185 & 234 & 168 & 172 & 240 \\
\hline Length/nm & $523 \cdot 3$ & $352 \cdot 1$ & $263 \cdot 3$ & $257 \cdot 1$ & $300 \cdot 8$ & $323 \cdot 0$ & $282 \cdot 0$ \\
\hline Side of cone $/ \mathrm{nm}$ & $64 \cdot 7$ & $70 \cdot 3$ & $67 \cdot 9$ & $67 \cdot 6$ & $67 \cdot 3$ & $66 \cdot 6$ & $66 \cdot 2$ \\
\hline Collapsed width/nm & $95 \cdot 4$ & $88 \cdot 0$ & $83 \cdot 9$ & $84 \cdot 8$ & $82 \cdot 6$ & $77 \cdot 1$ & $74 \cdot 1$ \\
\hline Gas vesicle density $/ \mathrm{kg} \mathrm{m}^{-3}$ & 159 & 179 & 194 & 193 & 192 & 203 & 213 \\
\hline Diameter/nm & $61 \cdot 3$ & $56 \cdot 6$ & $53 \cdot 9$ & $54 \cdot 5$ & $53 \cdot 1$ & $49 \cdot 6$ & $47 \cdot 7$ \\
\hline Group mean diameter/nm & $61 \cdot 3$ & $56 \cdot 6$ & & $53 \cdot 8$ & & $48 \cdot 6$ & \\
\hline Group standard error/nm & $0 \cdot 15$ & $0 \cdot 22$ & & $0 \cdot 21$ & & $0 \cdot 15$ & \\
\hline
\end{tabular}
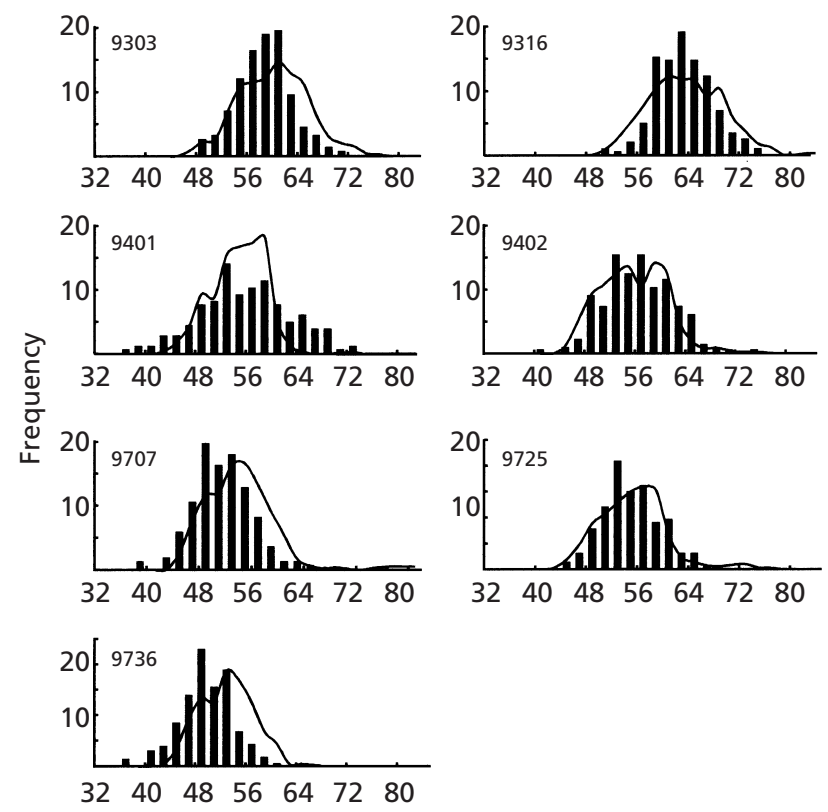

Gas vesicle diameter class/nm

Fig. 3. Histograms of gas vesicle diameters measured by electron microscopy in seven strains of Planktothrix, compared with the theoretical diameters (lines) calculated from the $p_{c}$ distributions by using equation (3).

Walsby, 1986) has previously been described by the negative exponential expression

$p_{\mathrm{c}}=275(\mathrm{r} / \mathrm{nm})^{-1 \cdot 67} \mathrm{MPa}=875(\mathrm{~d} / \mathrm{nm})^{-1 \cdot 67} \mathrm{MPa}$

where $r$ is the radius and $d$ is the diameter of the central cylinder of the gas vesicle (Walsby \& Bleything, 1988).



Fig. 4. Relationship between mean $p_{c}$ and cylinder diameter of gas vesicles in seven strains of Planktothrix rubescens $(\triangle)$ and the species of cyanobacteria investigated by Walsby \& Bleything (1988) (O) and Kinsman (1995) (O). The solid line indicates the exponential relationship of $p_{d} / d$ calculated from equation (2), using all the data; the dashed line is calculated from equation (1), excluding the new data on Planktothrix gas vesicles.

Our new measurements of gas vesicle $p_{\mathrm{c}}$ and width in Planktothrix rubescens extend the range of the relationship to stronger and narrower gas vesicles (Fig. 4). With inclusion of these data the coefficients are recalculated, by using the Walsby \& Bleything (1988) procedure, as

$p_{\mathrm{c}}=160(\mathrm{r} / \mathrm{nm})^{-1 \cdot 53} \mathrm{MPa}=461(\mathrm{~d} / \mathrm{nm})^{-1 \cdot 53} \mathrm{MPa}$

It is seen that the new $p_{\mathrm{c}}$ values are only slightly lower than would be predicted by extrapolating the relationship defined in equation (1); inclusion of the new values gives little change in the relationship over the range of the original measurements (Fig. 4). 


\section{Comparison of measured gas vesicle width distribution and that calculated from $p_{c}$}

If the variation in gas vesicle diameter were the only cause of variation in $p_{\mathrm{c}}$ then the diameters of gas vesicles that collapsed at different pressures could be calculated from the relationship described in equation (2); rearranging gives

$d=\left(p_{\mathrm{c}} / 461 \mathrm{MPa}\right)^{-(1 / 1 \cdot 53)} \mathrm{nm}=55 \cdot 7\left(p_{\mathrm{c}} / \mathrm{MPa}\right)^{-0 \cdot 655} \mathrm{~nm}$

Using these values the frequency distributions of $p_{\mathrm{c}}$ shown for each strain in Fig. 2 were transformed into the frequency distributions of diameters shown in Fig. 3, where they are compared with the distribution of measured diameters. In most cases the means and standard deviations of both measured and calculated diameter distributions were fairly similar. This indicates that much of the variation in $p_{\mathrm{c}}$ could be explained by variation in gas vesicle width.

\section{The range of gas vesicle length}

Measurements were also made of the lengths of the gas vesicles and, when they were not distorted by collapse, of the sides of the collapsed cones (up to 20 in each strain). From these measurements, using procedures described by Walsby \& Bleything (1988), the mean volumes of wall $\left(V_{\mathrm{w}}\right)$ and enclosed gas space $\left(V_{\mathrm{i}}\right)$ could be calculated for gas vesicles of each strain. The ratio of these volumes can be used to calculate the buoyant density of the gas vesicles (Table 2), which is inversely related to their efficiency in providing buoyancy. The relatively high densities, from 159 to $213 \mathrm{~kg} \mathrm{~m}^{-3}$, are principally a consequence of the small widths.

Increased length carries no penalty in $p_{c}$, and brings some decrease in density. It might be expected, therefore, that where narrow gas vesicles are required to withstand high pressures, they should be made as long as possible. Paradoxically, those in six of the seven Planktothrix strains are shorter (in the range of $257-352 \mathrm{~nm}$ ) than those in most other cyanobacteria. The ratio of $V_{\mathrm{i}} / V_{\mathrm{w}}$ in the conical end caps is lower than that in the central cylindrical part of a gas vesicle and for this reason the overall value of $V_{\mathrm{i}} / V_{\mathrm{w}}$ increases with gas vesicle length but asymptotically approaches a maximum value. For gas vesicles with diameters less than $60 \mathrm{~nm}, 90 \%$ of the maximum $V_{\mathrm{i}} / V_{\mathrm{w}}$ ratio is obtained at lengths exceeding $260 \mathrm{~nm}$ (see Fig. 6 of Walsby \& Bleything, 1988). The gas vesicles in all of the strains exceed this efficiency level.

\section{Correlation of $p_{c}$ with genotype}

Beard et al. (1999) determined the GV genotypes of the 81 strains of Planktothrix investigated here. The three different classes of GV genotype are distinguished in the frequency distribution of mean $p_{\mathrm{c}}$ values in Fig. 1: the $p_{\mathrm{c}}$ ranges were $0 \cdot 96-1 \cdot 0 \mathrm{MPa}$ for the 3 isolates of GV1, $0.86-0.99 \mathrm{MPa}$ for the 26 isolates of GV2, and
1.0-1.17 MPa for the 52 isolates of genotype GV3. No distinction can be drawn between the $p_{\mathrm{c}}$ values of GV2a and GV2b or between GV3a and GV3b. The $p_{c}$ distributions of genotypes GV2 and GV3 are nonoverlapping and clearly different. (That of genotype GV1 appears to be mid-way between the other two, but the number of isolates of this genotype available is too small to allow firm conclusions to be drawn.)

The gas vesicle gene cluster of genotype GV2 is distinguished by having three copies of a $g v p C^{20}$ gene, whereas that of GV3 has three copies of the smaller homologous $g v p C^{16}$ gene as well as a copy of $g v p C^{20}$ (Beard et al., 1999). A possible explanation for the observed correlation between phenotype and genotype is that the smaller $\mathrm{GvpC}^{16}$ product of the $g v p C^{16}$ gene causes narrower gas vesicles to form (perhaps by causing the growing conical cap to extend as a cylinder at a smaller diameter); the resulting narrower gas vesicles would have a higher $p_{\mathrm{c}}$.

If this explanation is correct then the size of the GvpC molecule must have two opposing effects on gas vesicle strength. Kinsman et al. (1995) showed that when Anabaena gas vesicles were stripped of their native GvpC (containing five 33-residue repeats, 33RRs) and then allowed to bind recombinant GvpCs containing different numbers $(2-5)$ of the 33RRs the resulting $p_{c}$ increased with number of 33RRs. In those experiments, however, the width of the gas vesicles would already have been fixed, during their formation; the restrengthening that occurred on rebinding GvpC then depended on the number of ribs each molecule crossed, a function of the number of 33RRs. What we are suggesting here is that during gas vesicle assembly the number of 33RRs also influences the diameter of the gas vesicle that forms and this is a major determinant of critical collapse pressure (Walsby, 1982).

There is some variation in mean $p_{\mathrm{c}}$ between different strains within each GV genotype (Fig. 1) and it is possible that they contain additional genetic differences that affect gas vesicle collapse. These might include changes in other gvp genes (Kinsman \& Hayes, 1997) or minor differences in nucleotide sequence within $g v p A$ or gvpC that do not change the lengths of the PCR amplification products used to characterize each GV genotype (Beard et al., 1999). It is noted, however, that the sequence of $\mathrm{GvpC}^{20}$ in strain Pla 9736, which has the narrowest and strongest gas vesicles (Table 2), differs in only one amino acid residue (proline instead of serine at residue 150) from that of Pla 9401. Comparisons of Pla 9316 and Pla 9303, whose $g v p C^{20}$ s differ in the same way, suggest that this single amino acid change does not account for the difference in $p_{c}$.

At least part of the variation in mean $p_{\mathrm{c}}$ must be due to variations in the state or condition of the cultures. In clonal cultures of Anabaena flos-aquae the $p_{\mathrm{c}}$ varies with a standard deviation of $15 \%$ of the mean value of $0.615 \mathrm{MPa}$; about half of this variation is explained by variations in the width of gas vesicles (Walsby \& Bleything, 1988). Other causes of variation include the 
age distribution of the gas vesicles and physiological conditions that affect $p_{c}$ (Hayes \& Walsby, 1984). Values of mean $p_{\mathrm{c}}$ in different investigations may vary by $\pm 6 \%$. This is similar to the variation within the GV2 genotypes $( \pm 6 \%)$ and only slightly less than that within the GV3 genotypes $( \pm 8 \%)$.

\section{Natural selection of gas vesicle $\boldsymbol{p}_{\mathrm{c}}$ in Lake Zürich}

The natural selection of gas vesicle $p_{c}$ in populations of Planktothrix has been discussed in some detail by Walsby et al. (1998). Filaments with stronger gas vesicles maintain their buoyancy at greater depths during winter mixing of a lake and are then able to float up in the spring and contribute to the inoculum of the next season's population in the metalimnion. Filaments with gas vesicles that withstand the pressure at the deepest point of the lake would always form the greatest proportion of buoyant filaments. There is, however, a greater cost in producing stronger, narrower gas vesicles and this produces counter-selection for wider and weaker gas vesicles (Walsby, 1994). The compromise solution is determined by the balance of the cost in making stronger, narrower gas vesicles and the benefit of the additional filaments recruited to the metalimnetic population.

In Lake Zürich the population of Planktothrix rubescens is mixed down to great depths during the winter (Thomas \& Märki, 1949) and in cold winters is circulated to the deepest point of the lake at $136 \mathrm{~m}$ (Walsby et al., 1998). Gas vesicles with a $p_{\mathrm{c}}$ of $1.53 \mathrm{MPa}$ would be required to withstand the combination of cell turgor pressure $(0.2 \mathrm{MPa})$ and hydrostatic pressure at the deepest point of the lake $(1.33 \mathrm{MPa}$ at $136 \mathrm{~m})$. Filaments that have gas vesicles with the highest mean $p_{\mathrm{c}}$ of $1.17 \mathrm{MPa}$ would remain buoyant down to depths of $99 \mathrm{~m}$ (below which only $3 \%$ of the lake volume occurs), while those that have gas vesicles of the lowest $p_{c}$ $(0.86 \mathrm{MPa})$ would remain buoyant down to depths of only $67 \mathrm{~m}$ (below which is $17 \%$ of the lake volume).

Walsby et al. (1998) observed that in the mild winter of 1994-5 the mixing depth did not exceed $80 \mathrm{~m} ; 80 \%$ of the population remained above this depth and $78 \%$ of the filaments there retained their buoyancy. There would have been little difference in the selection of strains with the weakest and strongest gas vesicles. In the colder winters of 1993-4 and 1996-7, however, some mixing penetrated to the lake bottom and (in the latter year) only $25 \%$ of the filaments in the top $80 \mathrm{~m}$ remained buoyant. A much greater proportion of strains with the weakest gas vesicles would have lost their buoyancy and there would have been positive selection for strains with the strongest gas vesicle.

The fact that Planktothrix strains with both stronger and weaker gas vesicles persist in the Lake Zürich population indicates the dynamic nature of the selection process from one year to the next. A quantitative description of this process could be produced by determining the ratio of the different strains in relation to the depth of winter mixing in different years. It would be difficult to obtain unbiased quantitative samples by the isolation and culture of single filaments, but the ability to identify GV genotypes that correlate with different $p_{c}$ phenotypes could provide the quantitative information required (Beard et al., 1999).

\section{ACKNOWLEDGEMENTS}

We are grateful to Dr F. Schanz for collecting Lake Zürich samples for the isolation of cyanobacteria. We thank Drs S. J. Beard and B. A. Handley for cultures of the Planktothrix strains and for comments on the manuscript. This work was supported by a studentship to D.B. from the BBSRC and by grant GR3/10970 from the Natural Environment Research Council.

\section{REFERENCES}

Albertano, P., Di Somma, D., Leonardi, D., Canini, A. \& Grilli Caola, M. (1996). Cell structure of planktic cyanobacteria in the Baltic Sea. Arch Hydrobiol Suppl, Algol Stud 83, 29-54.

Allen, H. G. \& Bulson, P. S. (1980). Background to Buckling. London: McGraw-Hill.

Anagnostides, K. \& Komárek, J. (1988). Modern approaches to the classification system of cyanophytes. 3 - Oscillatoriales. Arch Hydrobiol 80, 327-472.

Beard, S. J., Handley, B. A., Hayes, P. K. \& Walsby, A. E. (1999). The diversity of gas vesicle genes in Planktothrix rubescens from Lake Zürich. Microbiology 145, 2757-2768.

Feuillade, J. (1994). The cyanobacterium (blue-green alga) Oscillatoria rubescens D. C. Arch Hydrobiol 42, 77-93.

Hayes, P. K., \& Walsby, A. E. (1984). An investigation into the recycling of gas vesicle protein derived from collapsed gas vesicles. J Gen Microbiol 130, 1591-1596.

Hayes, P. K. \& Walsby, A. E. (1986). The inverse correlation between width and strength of gas vesicles in cyanobacteria. $\mathrm{Br}$ Phycol J 21, 191-197.

Kinsman, R. (1995). Molecular and structural studies of the gas vesicles of bloom-forming cyanobacteria. PhD thesis, University of Bristol.

Kinsman, R. \& Hayes, P. K. (1997). Genes encoding proteins homologous to halobacterial Gvps N, J, K, F, \& L are located downstream of $g v p C$ in the cyanobacterium Anabaena flosaquae. DNA Seq 7, 97-106.

Kinsman, R., Walsby, A. E. \& Hayes, P. K. (1995). GvpCs with reduced numbers of repeating sequence elements bind to and strengthen cyanobacterial gas vesicles. Mol Microbiol 17, 147-154.

Komárek, J., Hübel, M. \& Hübel, H. (1993). The Nodularia studies 2. Taxonomy. Arch Hydrobiol Suppl 96, Algol Stud 68, 1-25.

Oliver, R. L. (1994). Floating and sinking in gas-vacuolate cyanobacteria. J Phycol 30, 161-173.

Thomas, E. A. \& Märki, E. (1949). Der heutige Zustand des Zürichsees. Mitt Int Ver Limnol 10, 476-488.

Utkilen, H. C., Skulberg, O. M. \& Walsby, A. E. (1985). Buoyancy regulation and chromatic adaptation in planktonic Oscillatoria species: alternative strategies for optimising light absorption in stratified lakes. Arch Hydrobiol 104, 407-417. 
Walsby, A. E. (1973). A portable apparatus for measuring relative gas vacuolation, the strength of gas vacuoles, and turgor pressure in planktonic blue-green algae and bacteria. Limnol Oceanogr 18, 653-658.

Walsby, A. E. (1982). The elastic compressibility of gas vesicles. Proc R Soc Lond Ser B 216, 355-368.

Walsby, A. E. (1991). The mechanical properties of the Microcystis gas vesicle. J Gen Microbiol 137, 2401-2408.

Walsby, A. E. (1994). Gas vesicles. Microbiol Rev 58, 94-144.

Walsby, A. E. \& Bleything, A. (1988). The dimensions of cyanobacterial gas vesicles in relation to their efficiency in providing buoyancy and withstanding pressure. J Gen Microbiol 134, 2635-2645.

Walsby, A. E. \& Klemer, A. R. (1974). The role of gas vacuoles in the microstratification of a population of Oscillatoria agardhii var. isothrix in Deming Lake, Minnesota. Arch Hydrobiol 74, 375-392.

Walsby, A. E., Utkilen, H. C. \& Johnsen, I. J. (1983). Buoyancy changes of a red coloured Oscillatoria agardhii in Lake Gjersjøen, Norway. Arch Hydrobiol 97, 18-38.

Walsby, A. E., Hayes, P. K. \& Boje, R. (1995). The gas vesicles, buoyancy and vertical distribution of cyanobacteria in the Baltic Sea. Eur J Phycol 30, 87-94.

Walsby, A. E., Avery, A. \& Schanz, F. (1998). The critical pressures of gas vesicles in Planktothrix rubescens in relation to the depth of winter mixing in Lake Zürich, Switzerland. J Plankton Res 20, 1357-1375.

Received 26 January 1999; revised 5 May 1999; accepted 14 May 1999. 